\section{Perceptions of factors associated with condom use to prevent HIV/AIDS among persons with physical disability in an urban town of Cameroon: a qualitative study}

\author{
Elvis E. Tarkang, ${ }^{1,2}$ Awolu Adam, ${ }^{3}$ \\ Maragret Kweku ${ }^{4}$ \\ 1Department of Population and \\ Behavioral Science, School of Public \\ Health, University of Health and Allied \\ Sciences, Ho, Ghana; ${ }^{2}$ HIV/AIDS \\ Prevention Research Network, Kumba, \\ Cameroon; ${ }^{3}$ Department of Family and \\ Community Health, School of Public \\ Health, University of Health and Allied \\ Sciences, Ho, Ghana; ${ }^{4}$ Department of \\ Epidemiology and Biostatistics, School of \\ Public Health, University of Health and \\ Allied Sciences; Ho, Ghana
}

\section{Abstract}

Persons with disabilities have been identified as one of the groups vulnerable to HIV, due to several challenges posed by their disabilities. They also suffer external stigma from their able bodied peers. However, they have largely been ignored as part of HIV prevention programs, largely due to the perceptions that they are not at risk, and information is not being accessible. About $5.4 \%$ of the Cameroon population lives with a disability. In Cameroon, no official statistics exist on perception of factors associated with condom use to prevent HIV among persons with disabilities, which creates a challenge for understanding the extent of the pandemic in this population. The objective of this study was therefore to investigate perceptions of factors associated with condom use among persons with physical disability in an urban town of Cameroon. The qualitative study from which this paper is based, used semi-structured in-depth interviews, conducted with a purposive sample of ten ( 5 male and 5 female) persons with physical disability, aged 18 years and above, in April 2015. The findings of this study as interpreted according to the components of the Health Belief Model, indicated that perceived susceptibility to HIV, perceived severity of HIV, perceived benefit of condom use, perceived barriers to condom use and perceived self-efficacy for condom use were the factors perceived by persons with physical disability, to be associated with condom use. It is therefore recom- mended that there should be educational programs in HIV/AIDS targeted specifically at persons with physical disability. These programs should pertinently promote the understanding and perceptions of persons with physical disability of the real threat of HIV/AIDS, and also equip them with condom negotiation skills and strategies to overcome barriers to condom use.

\section{Introduction}

According to the recent world report on disability, around $15 \%$ of the world population lives with a disability and $80 \%$ of persons with disabilities (PWDs) live in developing countries. ${ }^{1,2}$ People with disabilities have been identified as one of the groups vulnerable to HIV due to several challenges posed by their disabilities. They suffer internal stigma which is self-inflicted due to low self-esteem, and also suffer external stigma from their able bodied peers. However, they have largely been ignored as part of HIV prevention programs, largely due to the perceptions that they are not at risk, and information is not being accessible. A lack of such information means that they do not receive adequate and life-saving information about the virus, its mode of transmission and prevention, and how to stay uninfected. Therefore, PWDs are likely to have an increased risk for HIV infection, potentially being a key population in regard to this epidemic. $^{2}$ About $5.4 \%$ of the Cameroon population lives with a disability. ${ }^{3}$ However, there is not much literature on HIV/AIDS and people with disabilities in Cameroon. This is mainly because those who have been charged with HIV/AIDS control have not yet considered how HIV/AIDS affects people with disabilities. In Cameroon, no official statistics exist on the perceptions of factors associated with condom use to prevent HIV among PWDs, which creates a challenge for understanding the extent of the pandemic in this population. For the fight against HIV/AIDS to succeed, policy makers and organizations must pay due attention to the plight of people with disabilities.

Recognizing the need for appropriate and reliable data to help protect PWDs from HIV infection and achieve a better inclusion of disability in National AIDS Control Programs in Cameroon, we undertook this study with the objective of investigating the perceptions of factors associated with condom use to prevent sexual transmission of HIV among persons with physical disability in Kumba, Cameroon.

This is based on the fact that the condom is the single, most effective available technology to reduce the sexual transmission of HIV. ${ }^{4}$
Correspondence: Elvis E. Tarkang, HIV/AIDS Prevention Research Network, Cameroon (HIVPREC), P0 Box 36 Kumba, Southwest Region, Cameroon.

Tel.: +237.677.632064

E-mail: ebeyang1@yahoo.com

Key words: Cameroon; condom use; health belief model; persons with physical disability; urban town.

Contributions: EET conceptualized the study, designed the research instrument, interpreted the data and wrote the manuscript; $\mathrm{AA}$ and $\mathrm{MK}$ critically reviewed the manuscript; all authors approved the final manuscript.

Conflict of interest: the authors declare no potential conflict of interest.

Received for publication: 21 July 2015. Accepted for publication: 9 March 2016.

This work is licensed under a Creative Commons Attribution NonCommercial 3.0 License (CC BYNC 3.0).

(C) Copyright E.E. Tarkang et al., 2015

Licensee PAGEPress, Italy

Journal of Public Health in Africa 2015; 6:491

doi:10.4081/jphia.2015.491

\section{Materials and Methods}

This study used the qualitative research design, which aims at describing social phenomena and behaviors using rich contextual data that emphasize the subjective experiences of social actors. In-depth interviews provide a flexible tool for collecting narrative data describing interviewees' perspectives. The value of qualitative perspective has gained favor in social and behavioral health research, and in HIV/AIDS research in particular, where many of the social phenomena being studied are personal, intensively private and sometimes illicit. 5

Qualitative research methods are known to be appropriate and effective when little or nothing is known about the situation, as they do not require a predictive statement and therefore seek the answers to open questions. Qualitative methods are also an effective tool when the target is vulnerable, as is inevitably so, when focusing on PWDs. ${ }^{6,7}$

Kumba, where this study was conducted, is an urban municipal area in the Southwest region of Cameroon, with a total population of approximately 166,000 inhabitants. ${ }^{8}$ The Republic of Cameroon is divided into 10 regions. The North West and South West regions are predominantly English speaking while the other 8 regions are predominantly 
French speaking. The Southwest region where this study was conducted has HIV/AIDS prevalence of $5.7 \%$, which is above the Cameroon national prevalence. ${ }^{9}$

In this study, we examined the views of persons with physical disability, in their natural settings to assess the perceptions of factors associated with condom use to prevent HIV transmission. ${ }^{10}$ Participants for in-depth interviews were selected purposively through the associations for persons with disabilities, resulting in a snowball sampling effect. This resulted in 10 (5 male and 5 female) persons with physical disability for face-to-face semistructured in-depth interviews.

This technique is often used when the researcher has specific requirements for the sample and picks a subject who meets these strict criteria. ${ }^{10}$ To qualify for the study, participants had to be at least 18 years old and having physical disability. Data were considered saturated when no more new information were obtained. ${ }^{11}$

Interviews were conducted with the aid of an interview checklist and included probes for further questioning, ${ }^{10}$ covering questions on key factors associated with condom use to prevent HIV transmission. The interviews were conducted and audio-taped in Kumba by the first author, and sessions lasted about thirty minutes, and the audio-recordings were transcribed verbatim. To ensure accuracy, the transcriptions were cross-checked for inter-rater reliability by the first author who is a specialist in HIV research. ${ }^{2}$ Data were organized and coded using a thematic analysis. ${ }^{5}$ Quotes were edited for ease of reading but were not substantially altered. The quotations cited in this paper best represent the range of experiences and perceptions voiced around key themes. A theme was then defined as a common thread that runs through the data. ${ }^{13}$ To maintain anonymity, these quotes are identified by gender and age. The transcripts were then reviewed to confirm the findings until saturation was reached, and quotes that best illustrate common theme, identified. ${ }^{14}$ To assure quality of the data, the checklist was piloted with two physically disabled persons. Subsequently, some modifications were incorporated in the research instrument.

Participants were given verbal and written information about the study and signed an informed consent form before being interviewed. No personal or identifying information was retained within transcripts. All interviewees participated on a voluntary basis and no financial incentives were provided. Ethical clearance for this study was obtained from the School of Public Health, University of Health and Allied Sciences (UHAS), Ghana, Ethical Review Committee. Permission to conduct the current research was obtained from research and ethics committee of the HIV/AIDS
Prevention Research Network, Cameroon (HIVPREC) and from the Ministry of Social Affairs, Cameroon.

Past studies informed the development of the topic guide for the semi-structured indepth interviews. ${ }^{15}$

\section{Results}

The responses were grouped according to the main components of the Health Belief Model (HBM), namely: perceived susceptibility to HIV, perceived severity of HIV/AIDS, perceived benefits of condom use, perceived barriers to condom use and perceived self-efficacy for condom use. ${ }^{16,17}$

\section{Perceived susceptibility to HIV/AIDS}

The first concept of the HBM is perceived susceptibility. This defines an individual's beliefs about the chances of contracting a health condition. ${ }^{18,19}$ A person's perception that a health problem is personally relevant will contribute to taking the required action to prevent the health problem. For this to take place there must be activities that increase the individual's perception of one's vulnerability to the health condition. People who perceive themselves to be susceptible to HIV/AIDS would more likely use condoms to protect themselves from the sexual transmission of the disease. Participants in this study perceived that they were susceptible to HIV/AIDS according to the following quotes:

«We believe HIV exists because it has killed so many people, including the physically disabled» (Male; 41 years).

«Persons with physical disability are highly exposed to HIV infection because of their disabled conditions. They feel desperate and being desperate, when any man approaches them for friendship and sexual intercourse, they will always accept» (Female; 31 years).

«Persons with physical disability, especially women, are at high risk of contracting HIV because they are sexually desperate. When a physically-disabled person stays for a long time without having sex, he/she becomes very excited to the extent that anybody that approaches him/her for sexual intercourse, they will just accept, not knowing the person's HIV status» (Male; 45 years)

\section{Perceived severity of HIV/AIDS}

The second component of the HBM is the perceived severity. This refers to one's beliefs of how serious a condition and its consequences are. ${ }^{18,19}$ When one recognizes one's susceptibility to a certain problem or condition, it does not necessarily motivate one to take the necessary preventive actions unless one realizes that getting the condition would have serious physical and social implications. It is when one realizes the magnitude of the negative consequences of a condition, that one could take the necessary actions to avoid these negative consequences. ${ }^{20}$

Persons with physical disability must perceive HIV/AIDS as a serious infection that has severe consequences and implications on their physical and social lives, before they would adopt preventative actions (such as consistent condom use) against HIV/AIDS infection. Participants in this perceived HIV/AIDS as a serious infection, according to the following excerpts:

«HIV is a very serious illness because we have seen signs on the television of how people with the disease are suffering and also from the information we get from everywhere» (Female; 31 years).

«We know that HIV is a serious illness because many people stigmatize you when they know you are HIV positive» (Female; 35 years)

\section{Perceived benefit of condom use}

Perceived benefits refer to one's belief in the efficacy of the advised action to reduce the risk or seriousness of impact. ${ }^{20}$ The person needs to believe that by taking a certain action, it will help one to avoid or prevent a problem from occurring. It is this belief that gives a person confidence to take the action because of the expected outcomes. ${ }^{20}$ Persons with physical disability in this study perceived condoms to be beneficial in preventing HIV transmission. One of them put it this way.

«We know that when you contract HIV, there is no cure. I doubt the efficacy of the condom because it can burst during sexual intercourse. This can put you at risk of contracting HIV when you are having sex with an HIV positive partner. However, when you use the condom correctly, it can prevent HIV infection» (Male; 41 years).

\section{Perceived barriers to condom use}

Perceived barriers refer to one's belief in the tangible and psychological costs of the advised behaviours. ${ }^{18,19}$ There could be several barriers that affect people's decision to take particular actions. Perceived barriers to health actions include phobic reactions, physical as well as psychological barriers, accessibility factors, personal characteristics, possible blocks or hindrances to engage in preventive behaviors, including such factors as cost, inconveniences and unpleasantness. ${ }^{21,22}$

Perceived barriers also include 
costs, duration, complexity of the deserved behaviors and accessibility to services that would support taking and maintaining the required actions. It is only when persons realize that they have the capacity to deal with these barriers, that they would be able to take the necessary actions. ${ }^{23}$ Persons with physical disability in this study perceived some barriers to condom use, according to the following excerpts

«Sometimes when you go for condoms, people will ask what a disabled person is doing with condoms. This makes us to be shy when purchasing a condom» (Male; 41 years).

«Sometimes a disabled woman might feel shy to ask a male partner to use a condom, especially if the man meets her material and financial needs, for fear that the man might turn down the request» (Female; 35 years).

«Sometimes because of the mobility problems that people with physical disability face, their sexual partners may refuse to go and buy a condom, and this can lead to unprotected sexual intercourse, which can expose the physically disabled to HIV infection» (Male; 45 years).

«Condoms are not easily accessible for a physically disabled person because of poverty and lack of mobility aides» (Female; 26 years).

\section{Condom use self-efficacy}

Self-efficacy is one's ability to successfully take action. One should feel that one is capable of taking the necessary action correctly because it is that confidence that would motivate one to initiate and sustain the action. In this literature, self-efficacy refers to the confidence in one's ability to use condoms. ${ }^{18-20}$ Persons with physical disability in this study perceived low self-efficacy for condom use, according to the following excerpts:

«Most of the time, persons with physical disability cannot refuse sex with their partners if they refuse to use condoms because of low selfesteem» (Female; 35 years).

«Because of their physically disabled conditions, persons with physical disability usually stay for long without having sex; for this reason, if a sexual partner proposes not to use condoms, they will find it difficult to refuse » (Male; 45 years)

«A physically disabled person may be very shy to ask the sexual partner to use a condom for fear of losing the partner if the partner refuses to use it. This might push them to engage in unprotected sexual intercourse» (Female; 46 years).
«Young girls with disabilities feel privileged to have sex with an able bodied man and they dare not discuss condoms with such men» (Female; 26 years).

\section{Discussion}

The HBM asserts that the motivation for people to take action to prevent a disease is based on how strongly they believe that they are susceptible to the disease in question; whether the disease would have serious effect on their lives if they contract it; whether the suggested health intervention is of value; whether the effectiveness of the treatment is worth the cost; which barriers they must overcome to institute and maintain specific behaviors, and whether they can successful take the recommended action.

Persons with physical disability in this study were aware of their risk of contracting HIV. The physically disabled who are aware of their risk are more likely to take actions to prevent infection. Those who do not perceive themselves as being at risk of contracting HIV/AIDS might not take necessary steps to protect themselves from HIV transmission. In addition to the personal risk of contracting HIV of persons with physical disability, they should also be informed of the general risk of contracting HIV/AIDS. This implies that persons with physical disability should be duly informed about the real threat, of available statistics, of risk behaviors and the risks involved in any changes in personal sexual practices. Such knowledge might help the physically disabled to correctly estimate their personal risks of contracting HIV/AIDS. However, all information should be offered in a balanced way without causing panic or a sense that contracting HIV is inevitable, leading to HIV/AIDS fatigue and a careless attitude that might undermine healthy sexual practices.

The study also revealed that persons with physical disability manifested an overall accurate perception of their susceptibility to HIV/AIDS infection. Sexual education and HIV/AIDS health education should pertinently promote the understanding and perception of persons with physical disability of the real threat of HIV/AIDS. The pertinence of this point cannot be overemphasized.

Persons with physical disability in this study were aware of the severity of HIV/AIDS infection. HIV/AIDS health education programs should pertinently indicate that HIV/AIDS is an independent disease caused by a specific virus, the HIV, and that there is currently no cure for this. Program contents must point out that HIV/AIDS, is often found concurrent with other sexually transmitted diseases (STDs), but might be present in PLHIV in the absence of other STDs.

This study revealed that persons with physical disability believed in the effectiveness of condom use to prevent sexual transmission of HIV. However, knowledge and perceptions do not necessarily guarantee expected behavior. Sexual education and HIV/AIDS health education targeted at persons with physical disability should be much more than mere information giving sessions. These programs must depart from a multidimensional point of view integrating psychosocial and socio-cultural factors as well as gender etiquette, life skill training and personal alertness and preparedness.

This study also revealed that persons with physical disability perceived some barriers which could prevent them from accessing and using condoms during sexual intercourse. All these perceived barriers could deter persons with physical disability from using condoms consistently during sexual intercourse to prevent transmission of HIV. These barriers might be contributory to the fact that knowledge and perceptions do not always result in corresponding and expected behavior. Sexuality and HIV/AIDS education for persons with physical disability should aim at normalizing both HIV/AIDS and condom use. All these actions call for cooperation among multiple organizations such as schools, parents, the community, social centers and national health agencies involved in the sexuality education programs for PWDs.

The data revealed that persons with physical disability demonstrated low perceived self-efficacy to use condoms effectively. According to the HBM, persons with physical disability who perceived themselves to be susceptible to HIV/AIDS need to have the confidence that they can use condoms, before they could use condoms correctly and consistently to prevent HIV/AIDS. Persons with physical disability with low condom use self-efficacy might not use condoms consistently during sexual intercourse to prevent HIV/AIDS. The physically disabled who lack confidence in their ability to purchase condoms and negotiate their use may have a higher likelihood of engaging in unprotected sexual intercourse. Self-efficacy must be understood by persons with physical disability as a normal condition in which the individual must find him or herself. Program leaders should be always vigilant to detect possible changes in the self-efficacy levels of persons with physical disability. This might be established via open relationships with persons with physical disability via role plays, values clarification and open discussion groups in life skill training sessions.

Persons with physical disability are less likely to have access to information and services, since it is assumed that they are not sexually active. They are, therefore, less likely to 
have the skills and means to protect themselves against HIV infection. HIV programs must be accessible and meet the needs of persons with physical disability. Persons with disabilities may more often than not be denied the opportunity to articulate their specific needs or be heard, owing to their marginalized position in society. Like many individuals, persons with disabilities need and want access to HIV education, testing and treatment, as well as to broader sexual and reproductive health services. Persons with physical disability should be fully included in national HIV responses. National strategic plans on HIV must include good practice on disability. HIV must also be included as an integral part of disability rights strategies, initiatives and programs. Persons with physical disability are less likely to have access to information and services, since it is assumed that they are not sexually active. They are, therefore, less likely to have the skills and means to protect themselves against HIV infection. Negotiation skills with regard to condom use should be practiced through role play sessions during sexuality education.

\section{Conclusions}

Notwithstanding the limitation, persons with physical disability in this study perceived themselves to be susceptible to HIV/AIDS, and also perceived HIV/AIDS as a serious infection. They perceived condoms to be effective in preventing the sexual transmission of HIV. However, they perceived several barriers to condom use, and also manifested low confidence in their abilities to successfully use condoms. These factors are perceived to be associated with condom use to prevent sexual transmission of HIV/AIDS among persons with physical disability in urban Cameroon.

\section{Limitations}

Firstly, there is a chance of desirability bias, as participants may have responded to what they believe the interviewer wanted to hear and not an accurate representation of their opinions, perceptions and experiences. Nonetheless, being mindful of this, the author is a specialist in HIV research and he was not bias in the way he asked questions to the participants. Secondly, the use of purposive sample could be a limitation because the results of the study cannot be generalized to the larger population of persons with physical disability. Reaching people through Associations of persons with physical disability means that participants are likely to be members of the
Associations and therefore more likely to be active in the community. The researcher attempted to organize interviews through the Ministry of Social Affairs with the aim of a more representative sample who may or may not be members of the disabled Associations. However, due to poor weather, timing, etc., all attempts failed. This again highlights the challenges in reaching the most vulnerable hard to reach population of persons with physical disability. Nonetheless, this qualitative assessment was able to provide context and information on a topic where limited data is available.

\section{References}

1. WHO. World report on disability. Geneva: WHO; 2011.

2. UNAIDS. People with disabilities. The gap report. Geneva: UNAIDS; 2014.

3. Tchamgoue H, Nantchouang A. Chapter 16: Handicap. In: INS Institut National de la Statistique et ICF. International. Enquête Démographique et de Santé et à Indicateurs Multiples du Cameroun 2011. Calverton: INS et ICF International; 2012.

4. Holmes k, Levine R, Weaver M. Effectiveness of condoms in preventing sexually transmitted infections. Bull World Health Organ 2004;82:454-61.

5. Silverman D. Interpreting qualitative data: methods for analyzing talk, text and interaction. 3rd ed. London: Sage Publications; 2006. p 448.

6. Stone E. Disability and development. Leeds: The Disability Press; 1999.

7. Roux W. The challenges of change. Early childhood development: practice and reflections. No 15. Den Haag: Bernard van Lear Foundation; 2002.

8. Bureau Central des Recensement et des Etudes de Population. Livre rapport de presentation des resultats definitifs. Cameroon; 2010. Available from: http://www.statistics-cameroon.org/downloads/Rapport_de_presentation_3_RGPH. pdf

9. Republic of Cameroon. Demographic and health survey and multiple indicators cluster surveys. DHS-MICS 2011. Available from: http://www.statistics-cameroon.org/ downloads/EDS-MICS11/DHSMICS_ 2011_preliminary_report.pdf

10. Bowling A. Research methods in health: investigating health and health services. 2nd ed. Buckingham: Open University Press; 2012. p 16.

11. Glaser AG, Strauss AL. The discovery of grounded theory: strategies for qualitative research. Piscataway: Aldine Transaction: California; 1967.

12. Pitchforth E, van Teijlingen E. International public health research involving interpreters: a case study from Bangladesh. BMC Public Health 2005;5:71.

13. Richards L, Morse JM. User's guide to qualitative methods. Thousand Oaks: Sage Publications, Inc.; 2007.

14. Strauss A, Corbin J. Basics of qualitative research: techniques and procedures for developing grounded theory. Thousand Oaks: Sage Publications; 1998.

15. Kurth ACM, Moore A. Formative research for computer counselling intervention to support antiretroviral adherence. A state of the science meeting on intervention research to improve anti-retroviral adherence. Yale University; 2005.

16. Bartholomew LK, Parcel G, Kok G, Gottlieb NH. Behavior oriented theories used in health promotion. In: Allegrante J, McLeroy K, eds. Planning health promotion programs. San Francisco: JosseyBass; 2006. pp 81-135.

17. University of Twente. Health belief model. Available from: https://www.utwente.nl/cw/theorieenoverzicht/Theory\%20Clusters/Health\%20C ommunication/Health_Belief_Model/

18. Groenewold G, Bruijn B, Bilsborrow R. Migration of the health belief model (HBM): effects of psychology and migrant network characteristics on emigration intentions on five countries in West Africa and the Mediterranean region. Population association of America 2006 annual meeting. March 30-April 1, Los Angeles. Available from: http://paa2006.princeton. edu/papers $/ 60050$

19. Resource Centre for Adolescent Pregnancy Prevention. Theories and approaches. From: http://recapp.etr.org/recapp /index.cfm?fuseaction=pages.TheoriesHo me

20. Resource Centre for Adolescent Pregnancy Prevention. Health Belief Model. Available from: http://recapp.etr.org/recapp/index. cfm?fuseaction=pages.TheoriesDetail\&Pa geID $=13$

21. Rosenstock IM, Strecher VJ, Becker MH. Social learning theory and the health belief model. Health Educ Q 1988;15:17583.

22. Agha S, Karlyn A, Meekers D. The promotion of condom use in non-regular sexual partnerships in urban Mozambique. Health Policy Plan 2001;16:44-151.

23. Polit DF, Hungler BP. Nursing research: principles and methods; 6th ed. Philadelphia: Lippincott; 1999. 